\title{
Profile of Breast Diseases in Eastern Nepal
}

\author{
Amir Bajracharya ${ }^{1}$, Anang Pangeni ${ }^{2}$ \\ ${ }^{1}$ Dept of Surgery, Plastic \& Reconstructive Surgery Unit, Kathmandu Medical College, Sinamangal, \\ Kathmandu, Nepal, ${ }^{2}$ Civil Hospital, Kathmandu, Nepal
}

\begin{abstract}
Correspondence
Dr. Amir Bajracharya,

Dept of Surgery, Plastic \&

Reconstructive Surgery Unit,

Kathmandu Medical College,

Sinamangal, Kathmandu,

Nepal
\end{abstract}

Email:

amirbajracharya@hotmail.co $\mathrm{m}$

DOI: http://

dx.doi.org/10.3126/

jemsn.v12i3.15090

Article received: June $1^{\text {st }}$
2016

Article accepted: Sept $2^{\text {nd }}$

2016

\begin{abstract}
Background \& Objectives: Breast problems, benign or malignant are common in occurrence worldwide. Breast problems can present themselves in a number of ways like breast pain, nipple discharge, cystic lesions and more commonly a lump. Breast diseases are under reported and cancer is one of the leading causes of mortality in women. This prospective study was undertaken with an aim to study the profile of various breast diseases in eastern Nepal. Materials \& Methods: This is a prospective study of women with breast diseases conducted from March 2011 to February 2012. Inclusion criteria were women irrespective of age with breast diseases with or without complaints. Exclusion criteria were women having breast abscess and mammary fistula. Results: Out of 125 breast diseases 39 cases $(31 \%)$ had malignancy and 86 cases $(69 \%)$ had BBD. The overall mean age for BBD was 25.9 years, with range of 10-60 years. The mean age for malignant breast diseases was 45.6 years, with range of 28-67 years. All of the cases had breast lump as their presenting complaints whether they came out benign or malignant. $52.8 \%$ had no significant pain associated with lump; in malignant cases $35.8 \%$ had pain associated with lump. In benign cases $68.7 \%$ had no perceptible change in lump size. On ultrasound scan, $69 \%$ of the lesions were designated benign compared to $31 \%$ malignant features. FNAC resulted in $68 \%$ lesions to be classified as of benign nature and $32 \%$ as malignant / suspicious malignancy. Conclusion: BBD constituted $69 \%$ of breast diseases, and mostly fibroadenoma and FCC/FCD and commonest malignant lesion was infiltrating ductal carcinoma. The BBD peaked at the age of 21-30 years.

Key words: Benign breast disease; Malignant breast disease; Fibrocystic changes; Fibroadenoma
\end{abstract}

Citation: Bajracharya A, Pangeni A. Outcome Profile of Breast Diseases in Eastern Nepal. JCMS Nepal. 2016;12(3):89-93.

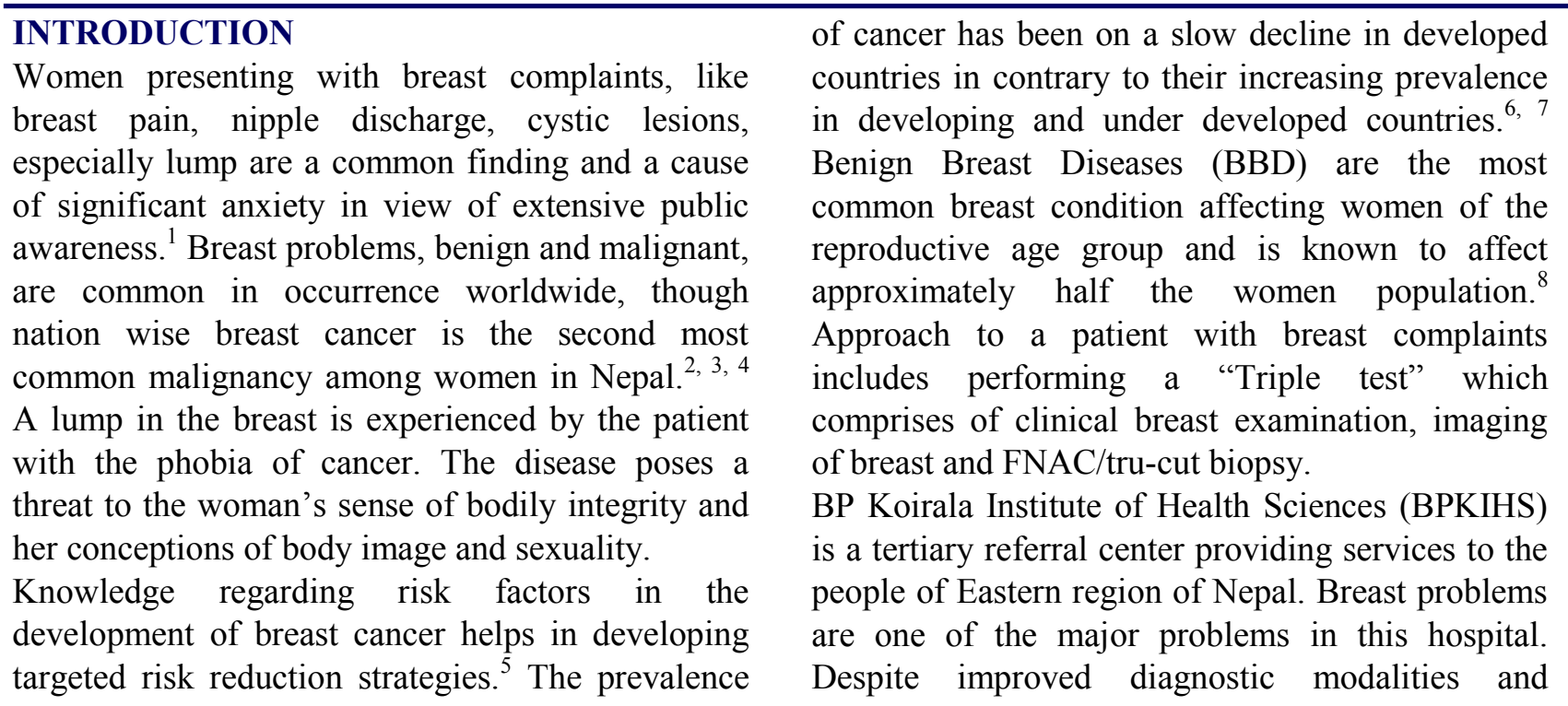


aggressive surgical intervention, outcome of breast problems is still poor. No data is available till date regarding the management of this problem in eastern Nepal population, in best of my knowledge. So this study is designed to evaluate the constraints of this problem in our developing country context. The purpose of this study is to have a specific management of breast problem within this framework, provide rationale for a current management plan, and anticipate evolving policy changes in the days ahead.

\section{MATERIALS AND METHODS}

A total of 125 patients over a period (March 2011 to February 2012) in surgical department of a tertiary care center in Eastern Nepal, B.P. Koirala Institute of Health Sciences, Dharan, Nepal, were taken up for study. Women, irrespective of age, with breast disease or lump with or without associated complaints were included, women having breast abscess and mammary fistula were excluded.

Initial data collection was done at surgical outpatient department (SOPD) by the attending doctor or the principal investigator. Further data collection were done during in-patient stay (if admitted for surgery) and during follow-ups at SOPD; from department of radio diagnosis and imaging, and the department of Pathology After focused history and physical examination patients with palpable breast lumps, who consented to the examination and management procedures were enrolled and followed. After a complete physical examination patients were sent for mammography and /or USG, then FNAC in such sequence. Data analysis was done by using SPSS v17.10.

\section{RESULTS}

Out of 125 cases, 31\% had malignancy and rest $69 \%$ patients had a benign lesion. One patient of 10 years age had juvenile fibroadenoma. The maximum patients were in the age group of 21-30 years, ranging 10-67 years. Fig: 1 shows distribution of patients according to age group in benign and malignant cases. All of the patients had breast lump as their presenting complaints, 52.8\% of patients had no significant pain associated with the lump. In malignant cases, 14 patients $(35.8 \%)$ only had pain associated with lump. In contrast, almost more than half of patients with benign lesions had some pain associated with the lump. The mean time lags before presentation after noticing the lump was 12.6 months. (table 1) Most

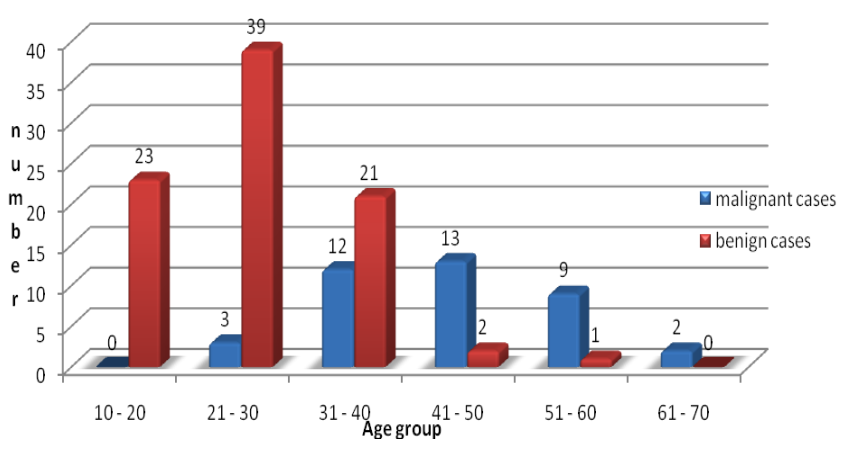

Figure 1: chart showing distribution of cases according to age group.

Table 1: Duration of lump before presentation

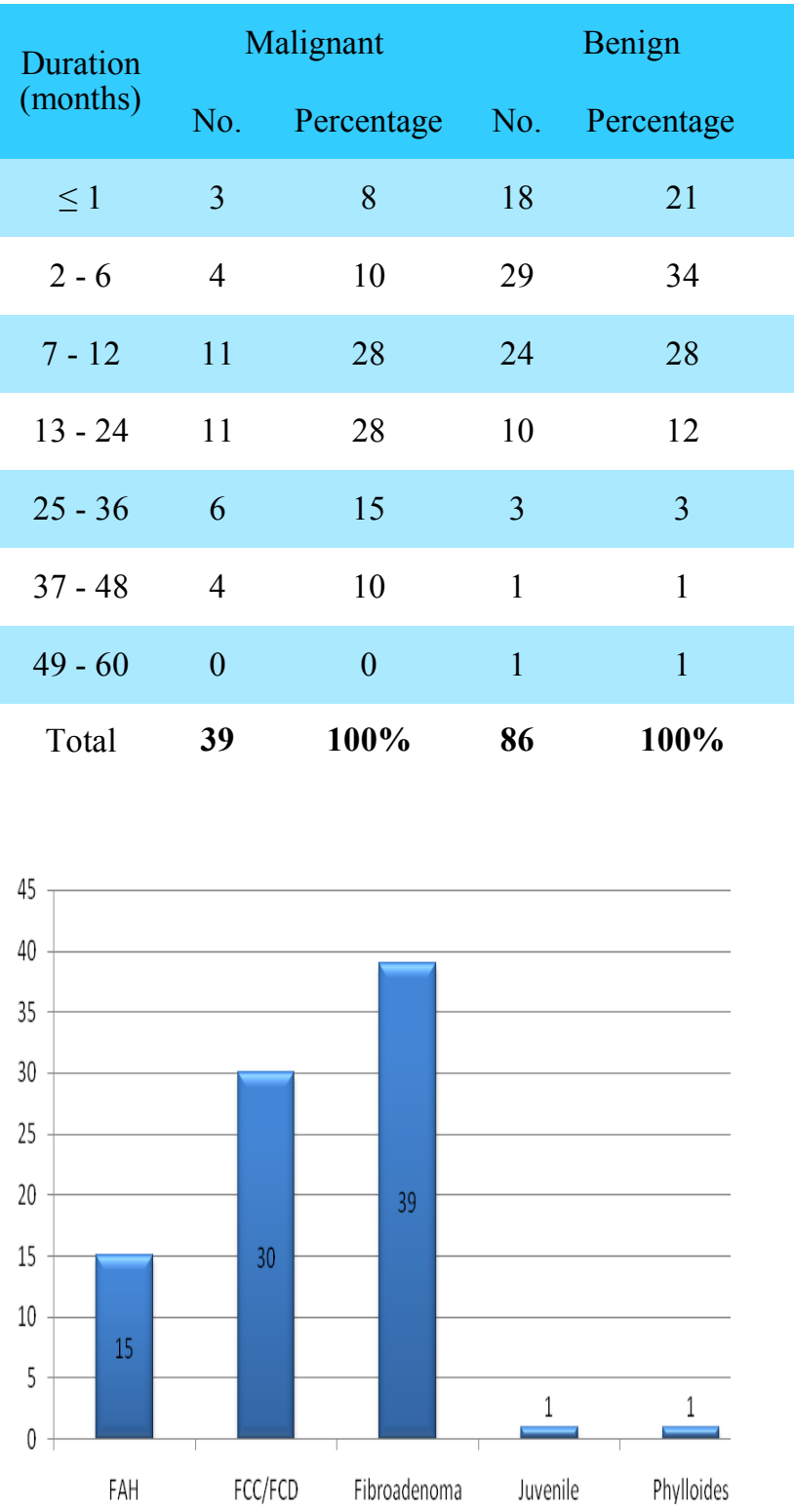

Figure 2: Different diagnoses of the breast lesions that were benign at histopathology 
of the patients presented for consultation after two to 12 months. Patients with benign disease presented much earlier than those with malignancy and this relation was statistically significant $(p=0.001)$. A total of $60.8 \%$ had not perceived a significant change in the size of lump after they first noticed $(\mathrm{p}=0.01)$. In benign cases $68.7 \%$ had no perceptible change in lump size, $56 \%$ of patients with malignancy had noted some increment in breast lump size before they presented to clinic. $27 \%$ of patients perceived pain as the first symptom; only 10 patients $(8 \%)$ of total patients had nipple discharge as associated symptoms. However, $20 \%$ of women with malignant lesion had noticed nipple discharge. Prevalence of smoking in patients with benign lesion was $9.31 \%$ whereas those with malignancy were $25.56 \%$. Out of 125 patients $19.2 \%$ were regular consumers of alcohol in which benign were 7 and malignant cases 17 . Most of the patients with benign lesions were seen to have earlier age at attaining menarche in contrast patients with malignancy had slightly late age at menarche.

Patients with benign lesions were mostly young females and had not attained menopause, $56.41 \%$ of patients with malignancy had not attained menopause. This shows that the incidence of malignancy in premenopausal women is more in this study. Out of 125 patients, $76 \%$ of patients breast fed their child for 2 years. $20 \%$ of patients with benign breast lesions and $36 \%$ of women with malignant lesions had used oral contraceptive pills. None of the patients with breast malignancy had history of breast disease in their 1st or second degree relatives. A total of $3.2 \%$ of patients had benign lesions in both the breasts, $64 \%$ of malignant lesions were in the right breast. Similarly, benign lesions also had right sided preponderance. $46 \%$ of malignant lump was in the right upper outer quadrant compared to $38.3 \%$ of benign lumps. Physical examination conducted in 125 patients had designated $72.80 \%$ of the lesions as benign, compared to $27.20 \%$ provisionally malignant lesions. On ultrasound scan, $69 \%$ of the lesions were designated benign compared to $31 \%$ malignant features. Of 27 patients who underwent mammography examination, $92.60 \%$ patients had malignant features. Since cut-off criteria for mammography was 40 year, and malignant cases were more in this group, above results are straightforward. FNAC resulted in $68 \%$ lesions to be classified as of benign nature and $32 \%$ as malignant/suspicious malignancy. Most common diagnosis in the benign group was fibroadenoma; Fibroadenomatoid hyperplasia classified separately here was diagnosis in 15 cases. Thirty nine patients had malignancy in which 32 had infiltrating ductal carcinoma, four patients had medullary carcinoma and three had colloid carcinoma.

\section{DISCUSSION}

Our study was a prospective study conducted over the period of March 2011 to February 2012 with an aim of studying the prevalence of breast diseases in Eastern part of Nepal. Out of 125 cases, 39(31\%) persons had malignancy and rest $86(69 \%)$ patients had a benign lesion. The maximum patients were in the age group of 21 to 30 years, mostly comprising of benign cases. Lump in the breast is a common premenopausal and post-menopausal physical finding in the female. Carcinoma of the breast is the most common site specific cancer in women and is the leading cause of death from cancer for females 40-44 years of age. ${ }^{9}$ Our study shows majority of patients had benign lump (68.8\%). In the present study 125 patients age ranging from 10 years to 67 years with a median age of 24 years for the benign group and $45.4 \pm 9.6$ years in the patients with malignant lesion. This finding is similar to some other studies; 49 years ${ }^{10}$ and 46 years. ${ }^{4}$

Time interval since the patient noted the lump to the time of presentation for consultation reflects the awareness and 'access to health' of the population. In our study the mean time of presentation was 12.6 months with a range of 15 days to 60 months. Most of the patients presented for consultation after two to 12 months. Patients with benign disease presented much earlier than those with malignancy and this relation was statistically significant $(p=0.001)$.

Since many women are not used to comprehensive self-breast examination, it is not surprising that women would find a lump on self-palpation of her breasts after a bout of pain. Majority of women with malignant lesions (64.10\%) had painless lump at presentation in comparison to $52.32 \%$ of patients who had painful lumps. As presented in above paragraph, the higher incidence of painful breast lumps could be one reason for benign disorders to present early for consultation. Only $36 \%$ of patients with malignant lumps had pain associated with the lump. Breast pain in our population is less likely to be a symptom of breast cancer which is also compatible to a study by Khan SA et al. ${ }^{12}$ 
Use of contraceptive for more than 5 years and its association to breast carcinoma has been a topic of discussion since decades. In our study, $20 \%$ of patients with benign breast lesions and $36 \%$ of women with malignant lesions had used oral contraceptive pills. Except for the two nulliparous women, all patients with malignant lesions had their first completed pregnancy by the age 20 . Similar is the findings on the women with benign lesions. Patients with benign lesions were much younger and had not yet married (26/86 i.e. $30.3 \%$ ). Nepalese breast cancer cases, particularly premenopausal breast cancer patients, are seen at a young age with late menarche, early first full-term pregnancy, long duration of lactation and a large number of children. ${ }^{12}$ Similar is the findings in our study: $64 \%$ of the patients are in the age group of 31 to 50 years, half of them $(31 \%)$ in the age group of 31 to 40 years; patients with malignancy had late menarche i.e. nearly $50 \%$ of the patients had their menarche at or above 14 years; $87 \%$ of patients with malignancy had breast feeding for more than two years and $74 \%$ of the patients had two or more children.

The prevalence of smoking was low in our patients compared to national data $(14.4 \% \mathrm{Vs} \quad 19.5 \%)$ however there were significantly higher proportion of smokers among the patients with malignant lesions. It was surprising to find none of the patients with malignant lesions had a positive family history. So did the patients with benign lesions. This is possibly due to small sized sample of our study; partly also because of less availability of these facilities in the past.

All the lumps were found more commonly situated at the upper and outer quadrants of the breast, $68 \%$ of the benign lumps and $76 \%$ of the malignant ones; compatible to findings with other studies and also because of the anatomical organization of the breast volume: more than $3 / 5$ th of breast tissue lies in this quadrant. As shown in figure 2, most common diagnosis in the benign group was fibroadenoma followed FCC/FCD, fibroadenomatoid hyperplasia, juvenile fibroadenoma and phylloides tumor respectively. Infiltrating ductal carcinoma was the commonest malignant lesion.

\section{CONCLUSION}

Based on our study, we conclude that benign breast diseases especially fibroadenoma are commoner than malignant ones. Lack of proper knowledge and awareness about screening programmes; like self breast examination, clinical breast examination and triple assessment, so it is suggestive and recommended that significant improvements need to be made regarding availability of such programs to the rural population.

FNAC resulted in $68 \%$ lesions to be classified as of benign nature and $32 \%$ as malignant /suspicious malignancy. Most common diagnosis in the benign group was fibroadenoma; Fibroadenomatoid hyperplasia classified separately here was diagnosis in 15 cases. 39 patients had malignancy in which 32 had infiltrating ductal carcinoma, four patients had medullary carcinoma and three had colloid carcinoma.

\section{REFERENCES}

1. Jan M, Mattoo JA, Salroo NA, Ahangar S.Triple assessment in the diagnosis of breast cancer in Kashmir. Indian J Surg. 2010 Apr;72(2):97-103. doi: 10.1007/ s12262-010-0030-7. PMID: 23133217.

2. Pradhananga KK, Baral M, Shrestha BM. Multiinstitutional hospital-based cancer incidence Data for Nepal: an initial report. Pradhananga KK, Baral M, shrestha BM. Asian Pac J Cancer Prev. 2009 Apr-Jun;10 (2):259-62. PMID: 19537894.

3. Vaidya BB, Fletcher AG. Incidence of malignant tumors in Nepal: A twelve year study. Journal of Nepal Medical Association souvenier. 1983;21:259-62.

4. Sayami P, Singh BM, Singh Y. Retrospective analysis of breast cancer cases and surgical treatment in a period of ten years. Journal of Nepal Medical Association. 2001;40:112-9.

5. Worsham MJ, Raju U, Lu M, Kapke A, Botttrell A, Cheng $\mathrm{J}$, et al. Risk factors for breast cancer from benign breast disease in a diverse population. Breast Cancer Res Treat. 2009;118(1):1-7. DOI: $10.1007 /$ s10549-008-01988. PMID: 18836828 .

6. Maiti PK, Gangopadhyay S. Changing trends in prevalence of cancer sites in west Bengal -a hospital based study. J Indian Med Asoc. 2012;110(11):803-06. PMID: 23785916.

7. Oslon RA, Nichol A, Caron NR, Olivotto IA, Speers C, Chia $\mathrm{S}$, et al. Effect of community population size on breast cancer screening, stage distribution, treatment use and outcomes. Can J Public. 2012;103(1):46-52.

8. Muka T, Imo D, Jaspers L, Colpani V, Chaker L, van der Lee SJ, et al. The global impact of non-communicable diseases on healthcare spending and national income: a systematic review. Eur J Epidemiol. 2015;30(4):251-77. 10.1007/s10654-014-9984-2. PMID:25595318.

9. SI, Swartz. Principles of Surgery. 7th. Edition. Vol. 1 Mc Graw Hill, 1999. pp. 533-599.

10. Morris A, Pommier RF, Schmidt WA, Shih RL, Alexander PW, Vetto JT. Accurate evaluation of palpable breast masses by the triple test score. Arch Surg. 1998 Sep;133(9):930-4. PMID: 9749842.

11. Khan SA, Apkarian AV. Mastalgia and breast Cancer : a prospective association? Cancer Detect Prev. 2002;26 (3):192-6. PMID: 12269765. 
12. Singh Y, Sayami P, Sayami G, Nakagawa H, Kooreeda T. Nepalese Breast Cancer in Relation to Reproductive Factors: Comparision between Nepalese and Japanese cases. Anticancer Research. 2002;22:319- 4. 